\title{
The change in the spatial configuration of the cells and membrane of the corneal epithelium in orthokeratology therapy experiment
}

\author{
S.L Pervykh* \\ Surgut state University, Medical Institute, Surgut, Russia
}

\begin{abstract}
To trace changes in the spatial configuration of the membrane and epithelium of the cornea, with full respect for the imitation of wearing orthokeratology lenses in the experiment.
\end{abstract}

\section{Introduction}

For the first time in Russia the issues of changes in the corneal epithelium in orthokeratology therapy were actively discussed by experts who are not ophthalmologists, United at the XII Congress of the International Association of Morphologists and VII Congress of the scientific medical society of anatomists, histologists and embryologists 28 - 31 may 2014 on the basis of the Tyumen State Medical Academy $[1,2]$. It was then in the discussion was asked the basic question: what are the changes of the epithelium of the full identity of the conditions of the experiment $[3,4]$. The study of patterns of implementation actions orthokeratology lenses payment progressive myopia is one of the leading areas of modern contact correction in ophthalmology $[5,6]$.

Despite the large number of studies on the morphological aspects of the development of the effect of orthokeratology therapy $[7,8]$, it is worth noting the main drawback in all studies - the wearing of orthokeratology lenses in the experiments with animals was permanent $[9,10]$. In our work we tried to consider this important point. The experiment was as close as possible to the real conditions of use of orthokeratology lenses patients. The choice as an experimental animal the rabbit is allowed to increase the number of individuals in the experiment (65 rabbits-animals compared with 15 cats).

\section{The purpose of the study}

To study the changes of cytoarchitectonics of chronobiology and epithelial cells of the cornea, with full respect for wearing orthokeratology lenses (orthokeratology simulation standard therapy) in the experiment with animals.

\section{Materials and methods}

The experiment consisted of 65 animals. Choice, taking into account the diameter and structure of the cornea, almost identical to the human, was made in favor of mature individuals of Soviet chinchilla breed. To ensure the full simulation orthokeratology therapy wearing lenses was performed in the night period using temporal bivariate for Golovin within 14 days (left eye of the animal). The right eye was used as control. Animals were removed from the experiment on the $15^{\text {th }}$ day in a humane way. After eye enucleating, the corneas were subjected to standard histological examination (staining with hematoxylin and eosin), followed by light microscopy.

\section{Results}

The studied material was represented by a complete (from limb to limb) slice of the cornea, passing through the optical center. The morphological study revealed the following features of the layers of the cornea, orthokeratology therapy subjected:

1. In the Central zone there has been a change of polarity of the cells, loss of normal nuclear-cytoplasmic ratio, lossof normal hierarchy, while preserving stratification (Figure 1).

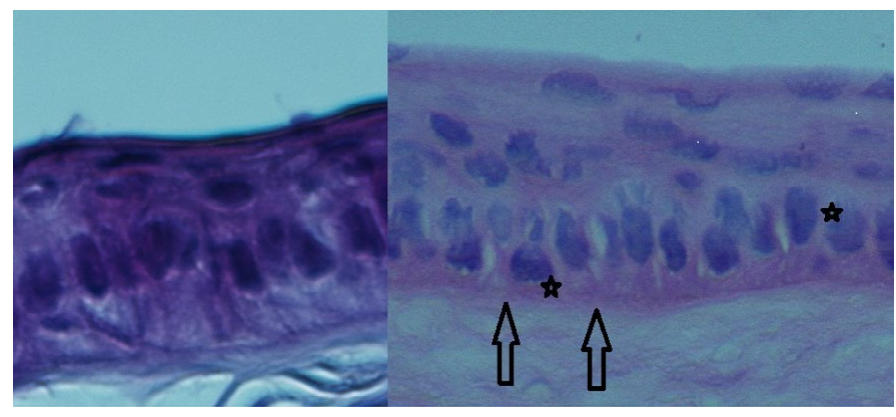

Figure 1. Stratified squamous epithelium of the cornea of the rabbit. Colouring with hematoxylin+eosin. Fill in paraffin. X 540. Comparison picture: left-control sample, to the right at OK-therapies. On the micrograph clearly visible layers of multilayer plane not becoming Horny epithelium to the underlying basal membrane and the anterior part of the stroma. In the control sample (left) preserved a strict orientation of the cells maintain their polarity, the localization of the nucleus. In the material subjected to OK-therapy, clearly visible the discontinuity and the violation of correct ternary structure of the basal membrane of the epithelium (arrow) and a disruption of cell polarity (asterisk).

Correspondence to: S.L Pervykh, Surgut state University, Medical Institute, Surgut, Russia; E-mail: luxer@yandex.ru

Key words: orthokeratology, epithelial changes, the basement membrane, nuclearcytoplasmic ratio, epithelial-stromal relationships

Received: May 11, 2016; Accepted: June 03, 2016; Published: June 06, 2016 
2. In all cases in the Central impact zone of the epithelium was formed defects (vacancies), different in length and depth (Figures 2 and 3 ).

3. In the return zone (zone of accumulation), there is a rough cell polymorphism, with a change in nuclear-cytoplasmic ratio, loss of cell polarity, hierarchy, stratification structure (Figure 4).

4. In addition to the changes of the epithelium along the entire length of the impact of orthokeratology lenses was observed, the response of the basement membrane of the epithelium: its intermittence, splitting, lack in some areas (Figure 5).

5. The change in basement membrane was observed in all histological sections 65 eyes subjected to OK-lenses.

\section{Conclusions}

The use of OK-lenses certainly affects the spatial geometry of epithelial cells. Change the configuration of the surface of the cornea is due to the transformation of cytoarchitectonics and epithelium in different areas of impact of the lens, and not the result cell migration. These conversions do not lead to clinically significant changes due to the high regenerative capacity of the epithelium. However, the primary

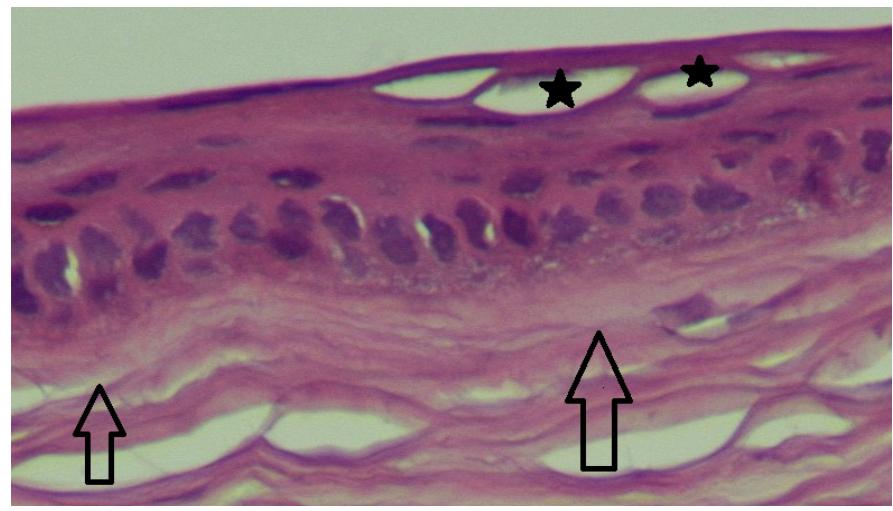

Figure 2. Stratified squamous epithelium of the cornea of the rabbit with OK therapy Colouring with hematoxylin+eosin. Fill in paraffin. X 270 . On the micrograph clearly visible layers of multilayer plane not becoming Horny epithelium to the underlying basal membrane and the anterior part of the stroma. Volumetric three-dimensional defects in the layer of flat cells (black asterisks) do not break the surface of the epithelium.

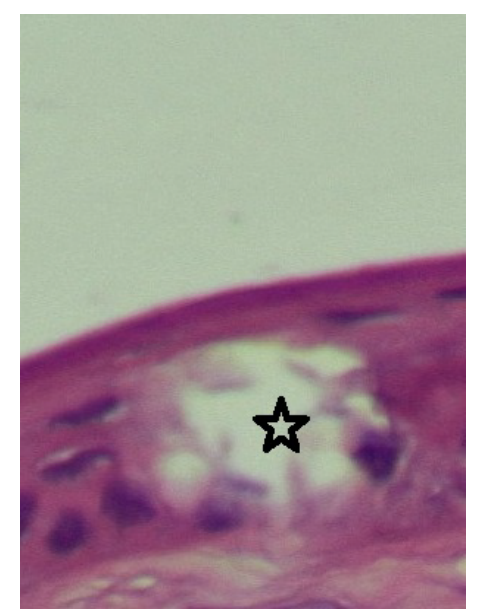

Figure 3. Stratified squamous epithelium of the cornea of the rabbit with OK therapy Colouring with hematoxylin+eosin. Fill in paraffin. X 540. On the micrograph clearly visible layers of multilayer plane not becoming Horny epithelium to the underlying basa membrane. Volumetric three-dimensional defect (asterisk) in the basal and spinous (wing cells) the layer does not violate the surface of the epithelium.

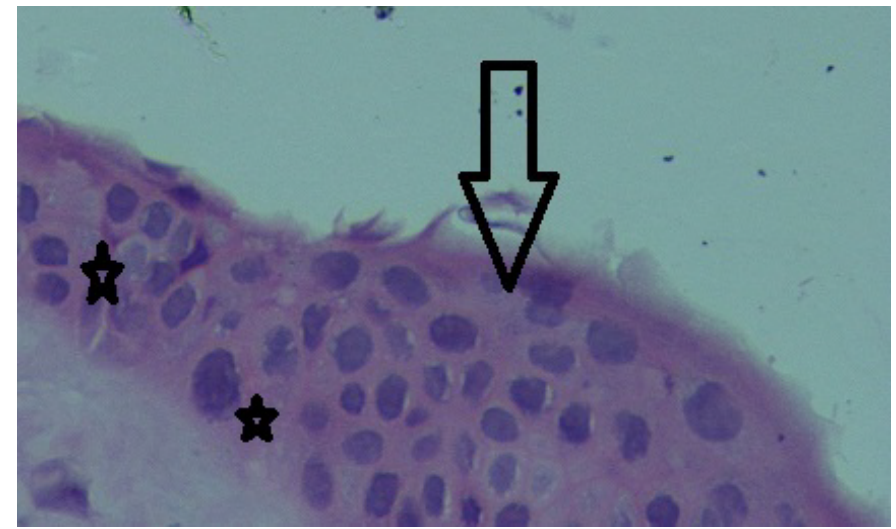

Figure 4. Stratified squamous epithelium of the cornea of the rabbit with OK therapy. Colouring with hematoxylin+eosin. Fill in paraffin. X 540. On the micrograph clearly shows changes in a polarity of normal cytoarchitectonics and a layered structure of the cornea. The displacement of the nucleus (arrows) of the basal layer of the epithelium and the orientation of the sides of the cells affect the General cytoarchitecture.

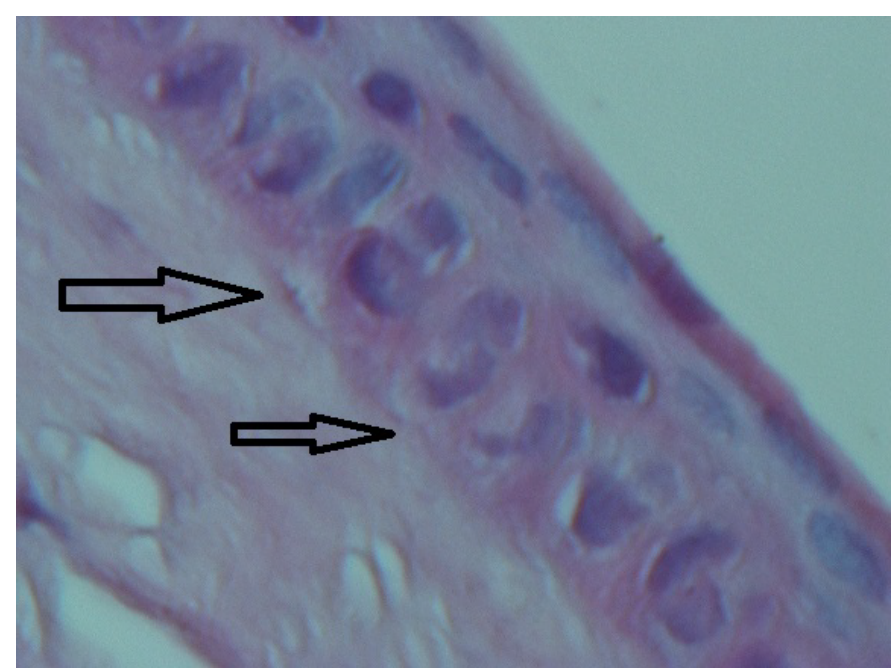

Figure 5. Stratified squamous epithelium of the cornea of the rabbit with OK therapy. Colouring with hematoxylin+eosin. Fill in paraffin. X 540. On the micrograph clearly visible layers of multilayer plane not becoming Horny epithelium to the underlying basal membrane and the anterior part of the stroma. Clearly visible the discontinuity and the violation of correct ternary structure of the basal membrane of the epithelium (arrows).

structure that regulates the life cycle of epithelial cells is the basement membrane, changes that we recorded. Remain open to explore the following questions:

1. What is the regenerative ability of the basement membrane?

2. What are the changes of the underlying structures?

What are the adaptive capacities of the epithelium and basement membrane in conditions of constant stress when wearing OK-lenses?

\section{References}

1. Cheah PS, Norhani M, Bariah MA, Myint M, Lye MS, et al. (2008) Histomorphometric profile of the corneal response to short-term reverse-geometry orthokeratology lens wear in primate corneas: a pilot study. Cornea 27: 461-470. [Crossref]

2. Choo JD1, Caroline PJ, Harlin DD, Papas EB, Holden BA (2008) Morphologic changes in cat epithelium following continuous wear of orthokeratology lenses: a pilot study. Cont Lens Anterior Eye 31: 29-37. [Crossref]

3. Matsubara M, Kamei Y, Takeda S, Mukai K, Ishii Y (2004) Histologic and histochemical changes in rabbit cornea produced by an orthokeratology lens. Eye Contact Lens 30: 198-204. [Crossref] 
Pervykh SL (2016) The change in the spatial configuration of the cells and membrane of the corneal epithelium in orthokeratology therapy experiment

4. Haque S, Fonn D, Simpson T, Jones L (2004) Corneal and epithelial thickness changes after 4 weeks of overnight corneal refractive therapy lens wear, measured with optical coherence tomography. Eye Contact Lens 30: 189-193. [Crossref]

5. Lam CS, Lam CH, Cheng SC, Chan LY (2014) Prevalence of myopia among Hong Kong Chinese schoolchildren: changes over two decades. Ophthalmic Physiol Opt 32: 17-24. [Crossref]

6. Chen D, Lam AK, Cho P (2010) Posterior corneal curvature change and recovery after 6 months of overnight orthokeratology treatment. Ophthalmic Physiol Opt 30: 274-280. [Crossref]

7. Reinstein DZ, Gobbe M, Archer TJ, Couch D, Bloom B (2009) Epithelial, stromal, and corneal pachymetry changes during orthokeratology. Optom Vis Sci 86: E1006-14. [Crossref]

8. Mao XJ, Huang CC, Chen L, Lü F (2010) A study on the effect of the corneal biomechanical properties undergoing overnight orthokeratology. Zhonghua Yan Ke Za Zhi 46:209-213. [Crossref]

9. Queirós A, Villa-Collar C, Gutiérrez ÁR, Jorge J, Ribeiro-Queirós MS (2011) Anterior and posterior corneal elevation after orthokeratology and standard and customized LASIK surgery. Eye Contact Lens 37: 354-358. [Crossref]

10. Wang Q, Leach N, Giannoni AG, Parker K, Miller W (2004) The effect of orthokeratology on corneal cell densities. Optom Vis Sci.

Copyright: $@ 2016$ Pervykh SL. This is an open-access article distributed under the terms of the Creative Commons Attribution License, which permits unrestricted use, distribution, and reproduction in any medium, provided the original author and source are credited. 